\title{
Engajamento com cidadãos: lições aprendidas na construção do Sistema Único de Saúde
}

\author{
Andrea Cornwall \\ Alex Shankland*
}

\begin{abstract}
Resumo
OSistema Único de Saúde (SUS) éum sistema universal, de financiamento público, baseado em direitos sociais à saúde, concebido e implantado em uma era em que as reformas neoliberais em outras partes do mundo têm impulsionado a mercantilização dos serviços de saúde, oferece lições importantes para os futuros sistemas de saúde. Neste artigo, focalizamos os mecanismos institucionais inovadores para a participação popular e prestação de contas (accountability) que fazem parte da arquitetura de governança do SUS. Nós argumentamos que esses mecanismos de participação pública têm o potencial de sustentar um pacto entre Estado e os cidadãos e assegurar o impulso político necessário para ampliar o acesso aos serviços básicos de saúde e, ao mesmo tempo, fornecer um quadro para o surgimento de "parcerias reguladoras", capazes de administrar a realidade complexa da assistência plural e de multiplicar as fontes de especialidades em saúde de uma forma que assegure que as necessidades e os direitos dos pobres e dos cidadãos marginalizados não sejam relegados para a periferia de um sistema de saúde segmentado.
\end{abstract}

\section{Introdução}

Sistema Único de Saúde (SUS) é um sistema universal, de financiamento público e baseado em direitos sociais. Projetado e desenvolvido durante uma época em que as reformas neoliberais de saúde em outras partes do mundo (e especialmente na América Latina) impulsionavam a mercantilização da saúde, o SUS apresenta uma série de liçōes importantes para o desenvolvimento de sistemas de saúde futuros. Os sistemas de saúde,

\footnotetext{
Este artigo foi originalmente publicado em inglês: Cornwall, A \& Shankland, A. (2008). Engaging citizens: lessons from building Brazil's national health system. Social Science \& Medicine, 66 (10), 2173-2184. O original está disponível no portal de periódicos da CAPES. A tradução foi realizada por Ana Carolina Campagnole dos Santos e André Kolb, com supervisão de Luciana Kind.

School of Global Studies, University of Sussex, Brighton, Inglaterra. E-mail: a.cornwall@sussex.ac.uk.

** Institute of Development Studies, University of Sussex, Brighton, Inglaterra. E-mail: a.shankland@ids.ac.uk.
} 
argumentam Bloom e Standing (2008), são baseados em dois tipos de acordos: entre o Estado e as profissóes, para restringir o acesso às especialidades mediante a profissionalização, em troca do poder de regular o acesso a bens e serviços por meios burocráticos; e entre o Estado e o mercado, fazendo uso de mecanismos de mercado para controlar o risco por meio de acesso limitado. Os autores argumentam que esses meios de "socializar" sistemas de saúde têm enfrentado, nas últimas décadas, uma série de desafios. A especialização em áreas da saúde é cada vez mais pluralizada, redefinindo o que significa ser um "especialista" e redesenhando as fronteiras do que é considerado como "conhecimento". Outros limites vieram a ser reconfigurados no processo: entre o público e o privado, entre os papéis do Estado e do mercado e entre os sistemas de Medicina.

Este artigo aborda uma dimensão ainda maior dessas mudanças: a do envolvimento dos cidadãos na deliberação sobre políticas de saúde, em mecanismos que assegurem a prestação de contas (accountability) e a tomada de decisões sobre as prioridades para a oferta de serviços em saúde. Os usuários dos serviços de saúde têm sido vistos tradicionalmente pela Medicina como receptores passivos de assistência médica e das informaçôes sobre saúde. Nos últimos anos veem-se deslocamentos guiados por mudanças culturais e políticas. Aqueles que, uma vez, foram considerados simplesmente como pacientes passaram a ser vistos como "usuários e agentes de escolha" (Cornwall \& Gaventa, 2001), com capacidade para exercitar preferências e buscar por serviços de melhor qualidade, seja por meio de reclamaçôes ou da troca de prestador de serviço (Hirschmann, 1970). A lógica dos "usuários como agentes de escolha" ganhou respaldo quase hegemônico nos sistemas de saúde no hemisfério Norte e também no Sul, guiando reformas impulsionadas por uma lógica de mercantilização e pela retórica da escolha.

O SUS se afasta significativamente dessa lógica em seu tratamento daqueles que buscam o acesso aos serviços de saúde como cidadãos imbuídos de direitos, em vez dos "clientes empoderados" (empowered clients). A Constituição Brasileira de 1988 estabeleceu a saúde como direito de todos, definiu a oferta de assistência como dever do Estado e garantiu o direito de participação civil na gestão da saúde, fundamentando o estabelecimento de mecanismos institucionais para a participação dos cidadãos nos níveis municipal, estadual e nacional. $\mathrm{O}$ movimento que levou à criação do SUS no Brasil surgiu de uma conjunção de elementos: a democratização das instituições políticas e sociais no período pós-ditadura; a mobilização bem-sucedida do movimento pela Reforma Sanitária, que ganhou impulso e influência na década de 1980; experimentações institucionais inovadoras que forneceram a inspiração para 
o desenvolvimento de mecanismos de envolvimento e responsabilização popular no âmbito da arquitetura do SUS; e um compromisso político com a prestação de serviços, com financiamento público, para todos os brasileiros.

Neste artigo, argumentamos que os dois últimos fatores são fortes norteadores para as formas pelas quais futuros sistemas de saúde poderão aprender com a experiência brasileira, enquanto enfrentam o desafio de "reconstituir arranjos institucionais que tenham em vista a mudança social" (Bloom \& Standing, 2008). Em particular, destacamos seu potencial para sustentar um pacto entre o Estado e os cidadãos que garanta o impulso político necessário para ampliar o acesso a serviços básicos de saúde ao mesmo tempo em que fornece um quadro para o surgimento de "parcerias reguladoras" (Bloom \& Standing, 2008) capazes de gerenciar a complexa realidade de uma prestação de serviços pluralista e, também, de multiplicar recursos especializados em saúde, de forma a garantir que as necessidades e os direitos dos cidadãos pobres e marginalizados não sejam relegados à periferia de um sistema de saúde segmentado.

Entre os desafios enfrentados pelos sistemas de saúde atuais e futuros, dois deles são chaves para a análise realizada por este artigo. O primeiro é democratizar o estabelecimento de prioridades, o que, em um contexto de recursos escassos e de contestação crescente dos valores e saberes que deveriam informar a sua destinação, é uma questão de conveniência política, assim como de ganhos em eficiência pragmática. O segundo é a criação de novos pactos entre os cidadãos e o Estado que possam reconfigurar as relaçôes nas múltiplas interfaces entre aqueles que utilizam os serviços de saúde e aqueles que os fornecem. A análise que se segue aborda esses dois desafios e explora a dinâmica de envolver os cidadãos na construção da saúde pública brasileira. Começamos traçando as origens e o desenvolvimento do Sistema Único de Saúde (SUS) e sua estrutura para a participação dos cidadãos. Em seguida, examinamos a participação civil por meio das descrições de três momentos de engajamento institucionalizado: a $12^{\text {a }}$ Conferência Nacional de Saúde, realizada em Brasília, em dezembro de 2003; a $4^{\text {a }}$ Conferência Nacional de Saúde Indígena, realizada em Caldas Novas (Goiás), em março de 2006; e a Conferência Municipal de Saúde, realizada em Cabo de Santo Agostinho, no Nordeste do Brasil, em abril 2006. Nossa análise busca tirar lições da experiência brasileira para tratar de um conjunto mais amplo de questóes sobre as possibilidades e os limites do envolvimento civil na construção e gestão de serviços de saúde, e sobre as perspectivas que essas liçôes podem contribuir para futuros sistemas de saúde. 


\section{O Sistema Único de Saúde}

É inquestionável que o SUS tem feito incursões substanciais na melhoria dos indicadores de saúde do Brasil. Entre 1992 e 2004, os indicadores nacionais de mortalidade de crianças com menos de 5 anos caiu de 65 para 27 a cada mil crianças (Ministério da Saúde, 2007), e a proporção de domicílios pobres com acesso a serviços de saúde aumentou quase pela metade, com a pesquisa de domicílios da PNAD registrando um aumento de 9,73\% em 1986 para 14,18\%, em 2003, no número de pessoas que declararam haver utilizado esses serviços nas duas semanas anteriores à pesquisa (Instituto Brasileiro de Geografia e Estatística, 2005; Silva, 2003). Em alguns lugares, as mudanças são drásticas. Em Cabo de Santo Agostinho, o lugar de um dos nossos estudos de caso, a taxa de mortalidade infantil caiu de 49/1 000 em 1994 para 10.5/1 000 em $2006,{ }^{1}$ devido, em grande parte, à reorganização da prestação dos serviços de cuidados primários em saúde e com a introdução bem-sucedida do Programa de Saúde da Família (PSF).

Há, ainda, muito a ser feito para melhorar a equidade em saúde. Apesar das melhorias no acesso, desigualdades significativas persistem, com diferenças importantes nos indicadores de saúde que se tornam evidentes quando os dados são separados por sexo, raça, renda e região (Oliveira, 2002). O consumo de planos de saúde privados pela classe média cresceu enormemente desde a introdução do SUS, com os gastos privados aumentando mais rapidamente do que os gastos públicos. A expansão do SUS foi pontuada por crises de financiamento e gestão, frequentemente refletidas nas histórias produzidas pela mídia sobre o colapso do serviço e seus abusos. No entanto, o SUS se manteve hegemônico, combinando ações redistributivas mediante a implantação de programas de cuidados primários, como o PSF, com tentativas cada vez mais assertivas de impor um controle regulatório sobre o crescimento do setor privado. Os cortes sucessivos nos recursos têm sido superados por mobilização política para gerar novas taxas de imposto exclusivo e proteger da austeridade da Receita Federal a parcela dos gastos públicos vinculados ao setor de saúde, resultando, em 2000, na aprovação Emenda Constitucional n ${ }^{\circ} 29$, que garante a alocação de uma parcela crescente dos recursos governamentais para o SUS. Como argumentamos anteriormente (Shankland \& Cornwall, 2007), a legitimidade do SUS deriva muito de uma poderosa "comunidade epistêmica” (Haas, 1992) comprometida com seus princípios embasados

${ }^{1}$ Relatório de Epidemiologia da Secretaria de Saúde de Cabo de Santo Agostinho, 2006. 
em direitos, que surgiu da luta para criá-lo. Esse fenômeno conseguiu se reproduzir, desde então, por meio do conjunto ímpar de instituições participativas do sistema de saúde brasileiro.

Os princípios do SUS (universalidade, atenção integral à saúde, equidade, descentralização e controle social) são o resultado de um intenso processo de renegociação dos modelos de serviços de saúde no País, durante o período pós-ditadura. Até os meados da década de 1980, os serviços de saúde curativos fornecidos pelo Estado eram concentrados nas cidades, e seus hospitais abertos apenas à minoria de trabalhadores que estavam empregados no setor formal (Costa, 2007). A exclusão sistemática gerava o descontentamento popular, mobilizando "movimentos populares de saúde" em vários locais, em todo o Brasil (principalmente na Zona Leste de São Paulo). Catalisadas por profissionais de saúde pública progressistas que vinham desenvolvendo abordagens alternativas em "saúde comunitária", com o apoio das universidades e da Igreja Católica, essas mobilizações locais se fundiram no movimento nacional pela Reforma Sanitária. Na transição da ditadura após 1985, os líderes do movimento, conhecidos como sanitaristas, ocuparam posiçóeschave nos níveis federal e estadual da burocracia da saúde (Costa, 2007; Melo, 1993; Weyland, 1995).

Foi o grupo de sanitaristas liderado pelo ativista do Partido Comunista, Sérgio Arouca (pesquisador carioca da Escola Nacional de Saúde Pública, que havia se tornado assessor do Ministério da Saúde durante a transição), que convocou a histórica 8a Conferência Nacional de Saúde, em 1986. As conferências de saúde anteriores haviam sido realizadas em encontros fechados, com tecnocratas e agentes do poder, mas, para a Conferência Nacional de 1986, o Ministério da Saúde reuniu milhares de ativistas comunitários de saúde de todos os cantos do País, em uma demonstração convincente do poder de mobilização do que tinha se tornado conhecido como o Movimento Sanitarista. A Conferência declarou que a saúde seria "o dever do Estado e o direito dos cidadãos", afirmou os princípios da universalidade, equidade, descentralização e participação, e gerou suficiente estímulo político para garantir que esses princípios fossem escritos na nova Constituição em 1988 e, posteriormente, no quadro jurídico, para torná-los operacionais com base na Lei Orgânica da Saúde de 1990 (Carvalho \& Santos, 1995).

O estabelecimento do SUS exigiu que negociações fossem feitas entre dois conjuntos-chave de protagonistas: governos municipais 
e o setor privado. ${ }^{2}$ Conquistar os primeiros foi essencial para alcançar a visão de descentralização do SUS no nível municipal, e necessitou de uma combinação de pressão política, incentivos fiscais e a criação de critérios e mecanismos transparentes de alocação de recursos (Arretche, 2003). ${ }^{3}$ A acomodação com o setor privado, pelo contrário, não foi o resultado de uma estratégia deliberada (o movimento sanitarista era visceralmente uma oposição à mercantilização), mas emergiu da derrota política do movimento: em direta oposição aos sanitaristas, os partidos conservadores conseguiram a inserção de disposições na Constituição que afirmavam a legitimidade do envolvimento do setor privado na área da saúde. Isso, por sua vez, sustentou a institucionalização de compra substancial de serviços de hospitais e clínicas privadas pelo SUS, dando aos fornecedores da área privada uma participação no sistema (Melo, 1993), e também deu legitimidade constitucional para os então emergentes planos de saúde privados, permitindo sua significativa expansão durante os anos 1990, antes de o SUS regulamentá-los no final daquela década.

Em 2003, Marta Arretche descreveu o estabelecimento e a consolidação do SUS como uma "mudança de paradigma", por meio da qual o País

Substituiu um modelo de assistência à saúde baseado no princípio contributivo e centralizado por um modelo em que o direito legal de acesso gratuito a ações e serviços de saúde em todos os níveis de complexidade é universal, e no qual a prestação de serviços está organizada de modo hierarquizado e descentralizado (Arrechte, 2003, p. 332, grifo no original).

A conclusão de Arretche (2003) foi que, embora exista um processo contínuo de ajustes nos mecanismos de gestão do sistema, o paradigma do SUS, baseado em direitos, tornou-se, ele próprio, institucionalizado, a tal ponto que era improvável sofrer qualquer mudança significativa. Nos termos usados por ativistas entrevistados durante nossa pesquisa, o SUS deixou de ser uma política de governo (uma política associada a um determinado partido ou regime) para se tornar uma política de Estado: uma distinção que contrasta políticas de governos particulares, que podem ser derrubadas pela próxima administração, com aquelas que se incorporaram ao próprio tecido do Estado e se tornam muito difíceis de suplantar.

\footnotetext{
Como mostrou Melo (1993), os esforços de lobby dos órgãos representativos de profissionais de saúde foram relativamente ineficazes no período entre a $8^{\text {a }}$ Conferência Nacional e o estabelecimento do SUS, impedindo qualquer possibilidade de que o novo sistema fosse baseado em um "pacto" entre Estado e profissionais, do tipo que deu origem ao Serviço Nacional de Saúde britânico.

Em 2002, 99,6\% dos municípios assumiram a responsabilidade de descentralização dos serviços básicos, acompanhando um crescimento de 23,4\% para 88,7\% no período de 1994-1998 (Arretche, 2003; Costa, 2002).
} 


\section{Participação institucionalizada no SUS}

O campo onde o movimento sanitarista teve sucesso absoluto foi na formação das disposições para participação dos cidadãos no sistema de saúde. A luta pela democratização no Brasil foi marcada tanto pela profunda desconfiança dos movimentos sociais em relação às tendências autoritárias e burocráticas do Estado quanto pelo desejo dos reformadores da saúde, alinhados com esses movimentos, em preservar o Estado como força motriz e local de políticas que visavam a abordar as profundas desigualdades do Brasil. Dessa tensão produtiva surgiu o princípio de "controle social" de políticas sociais implantadas pelo Estado e a formulação da participação como um direito.

As modalidades de institucionalização do controle social foram baseadas nas experiências formativas do movimento. Os Conselhos Populares de Saúde, que tinham sido estabelecidos por ativistas comunitários lutando por prestação de contas pelos serviços de saúde na Zona Leste de São Paulo, influenciaram a introdução de um quadro jurídico que tornou obrigatória em cada Município e Estado a criação de Conselhos de Saúde com paridade de representação entre representantes de usuários e prestadores de serviços. Os primeiros ocupavam $50 \%$ das cadeiras, enquanto $25 \%$ foram reservadas para trabalhadores da saúde e os $25 \%$ restantes destinadas a representantes das secretarias municipais e estaduais de saúde e provedores do setor privado contratados pelo Estado para prestação de serviços (Costa, 2007). Os conselhos receberam amplos poderes de supervisão sobre os gastos federais, e as transferências de fundos ficaram condicionadas à aprovação de orçamentos e de planejamentos em saúde. ${ }^{4}$ Da mesma forma, a experiência da $8^{a}$ Conferência Nacional de Saúde influenciou o projeto de criação de conferências periódicas em níveis local, municipal, estadual e nacional, que complementam a participação regularizada nos conselhos. $\mathrm{O}$ alcance capilar extraordinário dessas instituições envolve centenas de milhares de cidadãos na deliberação sobre políticas de saúde. As propostas são realizadas a partir do nível municipal até o nacional através de um sofisticado sistema de deliberação e votação em conferências em cada camada de governo. Como descreveremos, a tecnologia de participação utilizada pelo sistema de saúde brasileiro é, em si, uma inovação digna de atenção por outros países.

A crescente literatura sobre conselhos de saúde no Brasil descreve um quadro misto de sucesso dessas instituições na democratização da administração dos serviços de saúde (Coelho, 2004; 2006). Situado em um contexto em

\footnotetext{
4 Em 1999, 98,5\% dos 5560 municípios do Brasil criaram seu Conselho de Saúde (Melo \& Rezende, 2004).
} 
que rastros de uma cultura política autoritária e clientelista, altos níveis de burocratização e graus variáveis de organização cívica complicam a aspiração democratizante do controle social, poucos conselhos participativos parecem ter alcançado independência suficiente dos interesses políticos estabelecidos e suficiente competência civil em relação aos aspectos técnicos, gerenciais e financeiros do sistema de saúde para servir como espaços genuinamente deliberativos. Três dilemas principais surgem com base nessas análises. O primeiro é o dilema da autonomia e em qual medida os conselhos são capazes de efetivamente responsabilizar um Estado com o qual seus membros têm ligações múltiplas e complexas (Cornwall, 2006). O segundo é o da representação e até que ponto os conselhos, genuinamente, refletem a diversidade de interesses e atores sociais (Coelho, 2004; Tatagiba, 2002). E o terceiro é o das inerentes desigualdades de conhecimento e de poder entre os representantes dos usuários e os profissionais e gerentes de saúde (Viana, 1998; Dal Poz \& Pinheiro, 1998; Santos, 2000). A legitimidade democrática, bem como o potencial democratizante dos conselhos, depende da abordagem dessas questôes.

Mesmo com todos os desníveis de suas contribuições para a mudança das práticas de gestão do sistema de saúde, os mecanismos de participação do SUS abrem oportunidades para o envolvimento de uma enorme diversidade de atores sociais e políticos, desde movimentos nacionais e sindicatos a ONGs e associações comunitárias de pequeno porte. Programas de treinamento vastos e ambiciosos procuram capacitar os conselheiros de saúde com informaçôes básicas sobre o sistema de saúde, o orçamento da saúde e seus direitos como cidadãos. O efeito cumulativo de trazer "caras novas", como disse um gestor de saúde (Cornwall, 2006), aos espaços locais e com um nível superior de engajamento ao nível estadual e nacional tem sido com vistas a continuamente ampliar o envolvimento e comprometimento do cidadáo com o projeto do SUS. Isso tem emprestado a viabilidade política e resiliência que garantiu sua sobrevivência. Nas seções seguintes, examinaremos como a dinâmica desse processo se desenvolveu em três conferências recentes.

\section{A 12ª Conferência Nacional de Saúde de 2003}

A 12a Conferência Nacional de Saúde ocorreu em Brasília, um ano depois da eleição que elegeu o presidente Luís Inácio Lula da Silva, do Partido dos Trabalhadores (PT). O tema da Conferência, "A saúde que temos, o SUS que queremos", capturava as expectativas de que a chegada de um governo de esquerda poderia anunciar uma nova era para a melhoria da prestação 
de serviços públicos de saúde. Chamada de Conferência Sérgio Arouca, em homenagem ao falecido político comunista que desempenhou um papel tão vital na $8^{\text {a }}$ Conferência e nas disposições constitucionais para o SUS, a Conferência levantou expectativas adicionais em decorrência da promessa do novo ministro da Saúde de que, pela primeira vez na história do Brasil, o Plano Nacional de Saúde seguinte seria diretamente baseado nas conclusões da Conferência. Eleito por uma série de etapas, desde pré-conferências regionais no nível municipal a conferências de nível estadual, os mais de 3 000 delegados que foram a Brasília representavam uma incrível diversidade de interesses. A maioria, composta pela classe trabalhadora, viajou por horas ou mesmo dias de ônibus para chegar a Brasília, provenientes das favelas urbanas do Brasil, das distantes zonas rurais e do território vasto da Amazônia.

Um processo de preparação, que abrangeu os Estados e Municípios do Brasil, havia envolvido mais de 300 mil pessoas e gerado longas listas de propostas e demandas. Durante um período de quatro dias, a Conferência teve como objetivo discutir essas propostas e votar sobre as recomendações para a formulação de políticas. A gestão de um processo deliberativo, envolvendo mais de 3000 participantes é tão tecnicamente complicada quanto é politicamente complexa, e vale a pena considerar a forma como isso foi alcançado. A Conferência teve uma estrutura igual à que é adotada em todo o Brasil como parte de sua distinta tecnologia de participação, que tem vantagens dadas pela utilização de um sofisticado sistema de registro e agrupamento de alterações on-line em tempo real, usando um software especialmente desenvolvido para esse fim. Uma série de apresentaçôes principais foi realizada em um salão central, tratando dos temas da Conferência, que foram desde financiamento do serviço de saúde e supervisão pelos cidadãos até ciência e tecnologia. Todos os delegados foram informados, no início, com uma lista de propostas relativas a cada um dos temas. Enormes telas de vídeo no salão principal e em salas vizinhas mostraram os procedimentos do palco principal. Os delegados sentaram-se em silêncio para comparar, linha por linha, o documento enquanto cada palavra das políticas propostas era lida.

Os dados coletados pelo Ministério da Saúde sobre os participantes revelaram que cerca de $50 \%$ eram mulheres e mais de $40 \%$ se identificaram como negros. Menos de 30\% dos representantes dos usuários de serviços de saúde tinham formação universitária, e cerca de $71 \%$ de todos os delegados nunca tinham assistido a uma Conferência Nacional de Saúde anteriormente. Usando critérios para assegurar que a composição de cada grupo espelharia as diferenças regionais de origem e as filiaçôes institucionais dos delegados da Conferência, os participantes foram divididos em aproximadamente 100 
grupos de trabalho, com vários grupos responsáveis por deliberar sobre cada um dos 10 temas propostos pela Conferência. Ao longo de um dia, os grupos chegaram a um consenso sobre quais propostas deveriam aceitar, modificar ou rejeitar. Suas sugestôes foram inseridas diretamente nos terminais de computadores e projetadas em telas nas salas de reunióes menores, depois coligidas centralmente para a plenária do dia seguinte. Somente aqueles designados como delegados oficiais foram autorizados a votar, mas os "convidados" (como nós mesmos) foram autorizados a contribuir para os debates. As discussões ocorridas em ambos dos nossos pequenos grupos foram intensas, com níveis surpreendentemente elevados de participação, dada a diversidade dos grupos em termos de conhecimento médico, status, educação, gênero, raça e classe.

Pela observação de participante de um desses grupos, revelou-se que quase todos os participantes falaram pelo menos uma vez e que aqueles que mais falavam tinham tanta probabilidade de serem ativistas comunitários quanto profissionais da área de saúde. A qualidade desses debates e sua atenção a questôes de inclusão eram impressionantes, considerando-se a pressão sobre o processo de trabalhar com longas listas de propostas e chegar a um consenso. Esse problema foi administrado pela leitura da lista, enquanto as pessoas levantavam as mãos para marcar desacordo com uma proposta específica, o que era então registrado para discussão posterior. Uma vez que a primeira rodada de aprovaçóes era realizada, o grupo então considerava cada uma das objeçóes. A pessoa que registrava a objeção falava primeiro para sugerir uma alteração ou para tentar suprimir a proposta. O debate seguia para reformular a proposição ou para justificar a inclusão da proposta. Para dar um exemplo, um debate acalorado surgiu em um dos grupos em torno da menção de grupos particulares de interesse como foco de uma política específica: estavam divididos entre aqueles que argumentavam que, uma vez que o SUS prometeu o princípio de universalidade, não deveria haver tratamento especial para qualquer grupo, e aqueles que pretendiam expandir a lista dos que deveriam receber tratamento especial. $\mathrm{Na}$ fila para o almoço e em encontros fora do horário das sessões programadas, grupos de interesse faziam reuniōes e debatiam estratégias para proteger suas propostas; em um país tão vasto, a Conferência proporcionou oportunidades para formação de redes de trabalho e a consolidação de posições que seriam, de outro modo, mais difíceis de alcançar.

O debate na Plenária viu a calma deliberação dar lugar a uma acalorada argumentação conforme irrompiam controvérsias em torno de uma das áreas mais disputadas da política de saúde: os direitos reprodutivos. Os debates 
continuavam intensamente noite adentro. A certo ponto, um apelo veio do facilitador do debate para que os ativistas da Igreja Católica, que pulavam para cima e para baixo em frente à sala, "desistissem desse gesto antidemocrático" e se sentassem: eles estavam bloqueando a visão das pessoas em cadeiras de rodas que estavam atrás deles. A aparição do presidente Lula em determinado momento do processo trouxe aplausos extasiados, que depois se transformaram em pedidos para um retorno ao debate, enquanto a propaganda a favor do governo do PT se arrastava. A sessão plenária final continuou até altas horas, mas finalmente a lista de questôes contenciosas provou ser demasiado longa para o meticuloso sistema democrático de debates e votação conseguir dar operar dentro do tempo disponível. Como resultado, a 12 o Conferência Nacional de Saúde chegou a um conjunto incompleto de recomendações, que levou mais um ano para negociar o seu caminho através de reuniōes regionais de ratificações (fazendo impossível sua plena inclusão no Plano Nacional de Saúde). No entanto, se o impacto da Conferência sobre as políticas era questionável, seus impactos mais abrangentes sobre os movimentos que mobilizaram, reuniram, alistaram e redefiniram suas propostas em espaços fora da programação oficial não foram insignificantes, estimulando e revigorando suas energias e forças para lutar por seus direitos.

\section{A 4a Conferência Nacional de Saúde Indígena, Caldas Novas, 2006}

Um dos movimentos cujos representantes e aliados estavam ativos na utilização da $12^{\text {a }}$ Conferência Nacional de Saúde como espaço para pressionar o reconhecimento de suas reivindicações de direitos foi o dos povos indígenas do Brasil. Além de assegurar a inserção de referências específicas aos povos indígenas brasileiros como um grupo prioritário em várias resoluções da Conferência, o movimento também reivindicou a criação específica de uma "Conferência Nacional sobre a Saúde dos Povos Indígenas", que seria convocada no prazo de dois anos (Brasil, 2004).

Quando a $4^{\text {a }}$ Conferência Nacional de Saúde Indígena foi convocada, em março de 2006, já havia sido institucionalmente criado o "Subsistema de Atenção à Saúde Indígena”, formalmente em vigor no SUS. Criado em 1999, por meio de uma lei patrocinada por um dos idealizadores do SUS, Sérgio Arouca, e formalizada na Política Nacional de 2000, enfatizava 
tanto a participação indígena e a importância de sua medicina tradicional quanto estabelecia o princípio da interculturalidade (trabalhando, de forma respeitosa, através de fronteiras culturais), o Subsistema representava a primeira tentativa séria para tratar das necessidades e direitos de saúde específicos dos indígenas brasileiros, após cinco séculos de dizimação por epidemias, deslocamento e violência genocida. O Subsistema foi baseado nos Distritos Sanitários Especiais Indígenas (DSEI), gerenciado pela Fundação Nacional de Saúde (FUNASA), setor executivo do Ministério da Saúde, e era isento da obrigação de devolver o controle para os municípios (Athias \& Machado, 2001). Em 2006, 34 DSEI, cobrindo mais de 500 territórios indígenas reconhecidos no Brasil, tinham sido estabelecidos, e o gasto federal anual em saúde para os povos indígenas havia aumentado em 260\% desde o início da década, para mais de 100 milhões de dólares (Dias, 2006). Na definição do serviço de saúde indígena como um ramo específico do SUS, a legislação também procurou abordar as tensões entre um modelo "tamanho único" de universalização dos serviços e as demandas insistentes do movimento dos povos indígenas para o reconhecimento de diferenças tanto culturais quanto epidemiológicas.

Apesar desse nível de harmonização política e financeira sem precedentes, os meses que antecederam a Conferência foram dominados por expressões de descontentamento indígena, incluindo as amplamente divulgadas ocupaçôes dos escritórios regionais da Funasa por guerreiros de arco e flecha, protestando contra a persistência de mortes evitáveis entre os seus parentes nas aldeias. $\mathrm{O}$ movimento indígena e organizações não governamentais aliadas culparam a Funasa pela falha do subsistema em cumprir suas promessas, citando atrasos repetidos nas transferências de recursos financeiros para os DSEI, acarretando a falta de medicamentos e remuneração das equipes médicas (Instituto Socioambiental, 2006). Além dos problemas de gestão profundamente arraigados associados com a dependência da Funasa sobre a terceirização para garantir a prestação de serviços, acusações de corrupção proliferaram com a crescente penetração nos escalóes superiores da Funasa de pessoas nomeadas por partidos políticos clientelistas que se uniram à coligação parlamentar do governo Lula (Instituto Socioambiental, 2006). Como resultado, a Funasa organizou uma conferência que parecia destinada a ser dominada por desafios à legitimidade de seu mandato na gestão do Subsistema de Atenção à Saúde Indígena.

A escolha do local para a Conferência, um resort spa a algumas horas de carro de Brasília, desencadeou acusaçôes de que a Funasa estava tentando 
manter as vozes dissidentes dos indígenas longe dos tomadores de decisão e jornalistas da capital. Os organizadores da Conferência responderam às acusações, enfatizando a adequação de tal cenário silvestre para uma reunião com povos indígenas; reforçando um estereótipo de "filhos da Natureza" em desacordo com a realidade diversa dos grupos de povos indígenas do Brasil, muitos dos quais são, cada vez mais, urbanizados. $\mathrm{Na}$ cerimônia de abertura, delegados escolhidos a dedo desfilaram com ornamentação tribal completa. Um painel de dignitários elogiou o "nível sem precedentes de participação indígena" na Conferência. A única integrante indígena desse painel, a diretora do Fórum Nacional de Presidentes da Saúde dos Povos Indígenas, não foi solicitada a se pronunciar.

Conforme a Conferência progredia, tensões surgiram entre a retórica da interculturalidade e a realidade da aplicação rígida de práticas do SUS padronizadas para a deliberação política. Em uma longa e tediosa sessão de plenária, um representante do Conselho Nacional de Saúde leu um documento afirmando as regras para a conduta da Conferência, entremeada por hermética terminologia jurídica em latim. Nos grupos temáticos, em que os delegados consideravam centenas de propostas específicas recolhidas em conferências preparatórias locais e nos DSEI, delegados indígenas, usando estilos deliberativos tradicionais, foram repreendidos por desviar do tema e atrasar o processo, e foram lembrados de que apenas solicitaçôes escritas de forma apropriada poderiam ser aceitas para apresentação e submetidas à votação em plenária.

Embora houvesse pouca discordância sobre o conteúdo das recomendaçôes políticas da Conferência (até mesmo porque a política nacional existente já propunha uma série de melhorias buscadas pelos representantes dos usuários), o confronto se alastrou na plenária final, com a proposta de acabar com o papel de liderança da Funasa no Subsistema de Atenção à Saúde Indígena. Surgiu uma cisão entre os delegados do Nordeste, onde os representantes indígenas sentiam ter mais apoio da Funasa do que dos indiferentes e até mesmo hostis gestores municipais do SUS, e os da Amazônia, onde as organizaçôes do movimento se tornaram diretamente envolvidas na prestação de serviços e queixavam-se, amargamente, que seu trabalho havia sido paralisado pela interferência política e burocrática da Funasa (Shankland \& Athias, 2007). Capitalizando essa divisão e mobilizando todo o maquinário político clientelista (incluindo o sistemático arranjo das delegaçôes e a exclusão de potenciais dissidentes, mesmo aqueles que tivessem seu 
mandato de delegados pelas Conferências em seu Distrito), 5 os gestores da Funasa conseguiram derrotar um movimento que reivindicava que a responsabilidade pelo Subsistema fosse removida da agência e transferida para um novo Secretariado pela Saúde Indígena dentro do Ministério da Saúde.

Apesar do efeito alienante de práticas deliberativas impostas que não deviam nada à interculturalidade, do tom paternalista dos organizadores da Conferência, e da polarização amarga promovida pelo comportamento manipulador da Funasa, a maioria dos delegados indígenas entrevistados foi amplamente favorável sobre a sua experiência de participação na Conferência. A maioria nunca havia participado de um fórum político de grande escala como aquele. Apesar das coloridas armadilhas no discurso oficial da Conferência sobre a cultura indígena, os representantes não tinham expectativa de que aquele viria a ser um espaço o qual poderiam reivindicar como seu. Em vez disso, eles o identificaram precisamente como um espaço fornecido pelo "Estado branco" e executado de acordo com as suas regras. $\mathrm{Na}$ falta de uma plataforma política alternativa claramente definida em torno da qual poderiam se mobilizar, seus esforços foram investidos em aprender o máximo e o mais rápido possível sobre essas regras. Diversos entrevistados referiram-se às copiosas notas que haviam tomado, a compreensão que tinham adquirido por conversas com representantes indígenas de outras regióes e a riqueza de informações que seriam capazes de transmitir para sua comunidade (informaçôes que eles pensavam ser de grande valor para as lutas cotidianas pela prestação de contas nos postos de saúde e nas DSEI).

Estas lutas não foram domesticadas pelo fornecimento de espaços formais de participação popular - mobilizações de base e ações diretas para protestar contra as falhas da Funasa continuaram após a Conferência (ISA, 2006). Em vez disso, a Conferência proporcionou a oportunidade de adquirir conhecimentos e desenvolver habilidades para uso futuro, conforme a arquitetura de participação institucionalizada do SUS se torna incorporada ao Subsistema de Atenção à Saúde Indígena. A Conferência, considerada profundamente insatisfatória pelos ativistas de ONG e pelos líderes do movimento indígena (Dias, 2006), proporcionou, contudo, um passo significativo no caminho para um "acordo" entre o SUS e um dos grupos de cidadãos brasileiros mais vulneráveis e insubmissos. Os termos finais desse acordo ainda não foram definidos quando da

Fontes: Dias (2006) e entrevistas do autor com os delegados da Conferência e com o ex-assessor indígena de um DSEI na Amazônia. 
elaboração deste texto, mas o processo de engajamento de centenas de representantes indígenas de todo o Brasil permitiu que eles aprendessem como o sistema funciona e iniciassem o desenvolvimento de estratégias que podem, um dia, dar-lhes uma voz mais eficaz para garantir o respeito às suas necessidades específicas, aos seus direitos e aos seus saberes.

\section{Conferência de Saúde Municipal de Cabo, 2006}

Pouco mais de dois anos após a $12^{\text {a }}$ Conferência Nacional em Saúde, em abril de 2006, o Município de Cabo de Santo Agostinho, no Estado do Pernambuco, realizou a sua $6^{\mathrm{a}}$ Conferência Municipal de Saúde.

Atrasada pelas eleições de outubro de 2005, que tinham visto o populista Partido Trabalhista Brasileiro (PTB) assumir a administração municipal do esquerdista Partido Popular Socialista (PPS), a Conferência tinha como objetivos declarados discutir o Plano Municipal de Saúde, em vez de gerar propostas que seriam tomadas por meio da sequência de conferências em nível nacional. Nas várias pré-conferências, ocorreu o envolvimento de 700 pessoas de todo o Município. A Conferência, que reuniu 200 delegados e mais 50 convidados e observadores, ocorreu em uma instalação esportiva em uma das regiōes pobres do Cabo, apenas com projeçôes de Power Point em uma grande tela e amplificação do som no salão principal, sem outros grandes aparatos tecnológicos. Agrupados na parte de frente do salão, que tinha um formato de ferradura, os gestores de saúde se sentaram em bloco; o restante do salão estava cheio de "pessoas comuns" de todas as raças, a maioria das quais eram da classe trabalhadora.

A Conferência se iniciou com duas performances. A primeira foi um vídeo com cenas das pré-conferências, no qual o uso de música Brasileira em conjunto com legendas contendo frases sobre o Cabo era um resquício da propaganda da campanha eleitoral do partido. A segunda foi de uma ordem completamente diferente. Um grupo de teatro feminista fez uma grande interpretação de alguns dos graves problemas de acesso enfrentados pelas mulheres, alternando-os em cenas comoventes e hilárias. $\mathrm{O}$ vídeo enquadrou o populismo paternalista da administração e a saúde, emoldurado como uma questão de política e não de profissionalismo, questão que o eleitorado deveria confiar àqueles que teriam um interesse profundo por cuidar em seu nome. A peça de teatro subverte isso, ao colocar em cena o conhecimento das mulheres sobre sua própria saúde (ao não conseguirem receber os resultados dos testes prevenção de câncer de colo de útero, ao suportar partos sem assistência, ao serem menosprezadas por profissionais de saúde) no centro da questão. 
No dia seguinte, viu-se uma série de mesas-redondas formais nas quais especialistas reconhecidos (inclusive alguns trazidos de outras partes do Brasil) endereçaram à massa reunida os temas-chave da Conferência. Esses temas, que foram escolhidos mediante intensos debates no Conselho Municipal de Saúde, foram: a consolidação do SUS no Cabo, desafios para a gestão e controle social dos cidadãos, biotecnologia e de coordenação intersetorial. Os especialistas discursaram com paixão e eloquência, tentaram transmitir ao público, de maneira simples, termos técnicos e complexos, facilitando, assim, a compreensão. $\mathrm{O}$ olhar intenso de concentração nos rostos daqueles que estavam sentados, com suas camisetas da Conferência, alinhados de frente para o estrado, evidenciava seus esforços para captar a riqueza das informaçōes que estavam sendo dadas. Após um dia longo e quente, sentados em silêncio e ouvindo especialistas e altos oficiais do governo, os participantes mostraram poucos sinais de cansaço: uma contagem no início e no final do dia revelou algumas mudanças nos padrões de participação, como algumas das mulheres que deixaram o local para cuidar de crianças e mais homens participando depois do trabalho. A sala de conferências ficou completamente cheia até o final do dia.

$\mathrm{Na}$ manhã seguinte, os delegados convocaram os participantes para outra apresentação em mesas-redondas durante metade da manhã. Então, a partir do meio da manhã até o fechamento, às cinco horas, foi designada aos participantes a tarefa de trabalhar em pequenos grupos para percorrer as propostas acumuladas que vinham das pré-conferências em que os delegados foram eleitos. Em cada grupo, as propostas foram lidas, as objeçôes foram registradas e, em seguida, uma de cada vez, ou foi rejeitada ou alterada. Os estilos de deliberação foram variados, dependendo se os membros do grupo tinham experiência anterior de conferências ou não. A observação intensiva do participante de um grupo pequeno revelou uma eficiência impressionante. Não mais do que 10 minutos foram gastos em qualquer proposta, e as conclusões foram frequentemente alcançadas muito mais rapidamente; no final do dia, os grupos haviam aprovado, alterado ou rejeitado 176 propostas políticas e gerou um número ainda maior. As pessoas comuns, algumas das quais nunca tinham participado nesse tipo de evento, viram as suas propostas ou emendas aparecerem na tela do projetor. Uma mulher, na fila do almoço, exclamou para a amiga: "A minha proposta conseguiu passar, você pode acreditar nisso?". A alegria de sentir que realmente havia uma chance de influenciar a política era presente nos participantes.

Os conhecimentos negociados nos debates sobre determinados itens de política revela até que ponto as instituições participantes do SUS conseguiram 
equipar os representantes dos cidadãos com conhecimento técnico suficiente para chegar a julgamentos sobre áreas de política que poderiam ser considerados "muito técnicas" para a análise leiga. Um exemplo disso foram os debates sobre colposcopia e serviços de citologia cervical, que se espalharam pelos pequenos grupos e fizeram seu caminho em mais debates em plenário. Em um dos grupos, dois membros masculinos do Conselho Municipal de Saúde, ambos da classe trabalhadora e com baixos níveis de educação, debateram com um psicólogo e uma ativista do movimento de mulheres os prós e os contras das diferentes opções de parto. Um deles se manifestaria em plenário no dia seguinte para articular sua posição a favor da solução proposta pelo movimento de mulheres. O que ficou evidente nessas discussões é que onde a competência do cidadão atingiu os seus limites, profissionais de saúde entraram em cena: mas eles o fizeram para assim explicar, em termos leigos, o que estava em jogo. Grande parte da literatura sobre participação está preocupada com o que os cidadãos podem contribuir; ela negligencia, às vezes, o que eles podem aprender com os profissionais e "especialistas" e a partir desses processos de debate com outros cidadãos.

Outro exemplo da negociação dos saberes foi em relação à economia de definição de prioridades. A solicitação da construção de um hospital suscitou a intervenção da Secretaria Municipal de Saúde. Em vez de considerar as demandas dos usuários como irracionais, ela passou a prestar contas do retorno relativo de diferentes tipos de serviços e as escolhas que precisariam ser feitas para canalizar recursos para construção, para contratação de pessoal e para equipar um hospital. Seus argumentos foram aceitos, mas é uma prova da natureza do processo deliberativo que ele precisou oferecer uma justificativa bastante detalhada, e fazê-lo em termos que as pessoas sem conhecimento sobre orçamento público conseguissem seguir seu raciocínio. Teria sido muito fácil, afinal, simplesmente dizer que não há dinheiro para uma coisa como essa.

Os cidadãos trouxeram seus saberes para sustentar a discussão particularmente nos casos em que o conhecimento das condições locais superou a dos profissionais; precisamente o tipo de conhecimento para o qual defensores da democracia deliberativa, como Cohen e Sabel (1997), e Fung e Wright (2003) chamam a atenção. Rompendo com a bajulação dos gestores mais conhecidos estavam as vozes dos cidadãos de todo o Município, falando do que havia sido prometido e não entregue e de experiências em clínicas, nas filas, nos bairros onde os médicos ausentes deixavam encalhar pacientes sem assistência. Houve, nessa conversa, uma atmosfera não de confronto, mas de indignação: como o governo cumpriria bem suas promessas? 
Ao final de três intensos, longos e quentes dias de debates, a sala de conferências ainda estava cheia de pessoas; no dia das plenárias, os delegados trabalharam bem na parte da tarde, sem fazer paralisação para o almoço, a fim de garantir o consenso sobre as propostas da manhã. O compromisso daqueles que faziam parte do processo era evidente. Uma das partes mais empolgantes da Conferência veio no final. Depois de todas as recomendações serem aprovadas, uma moção foi proposta na assembleia para que a prática de ter uma mesa de almoço separada para o secretário de saúde e sua equipe não fosse repetida em eventos posteriores. Pela primeira vez em três dias de discussão ordenada, houve tumulto quando pessoas em todo o salão torcia, aplaudia e protestava. A moção foi encaminhada, mesmo com a desaprovação do secretariado. Quando as pessoas saíam de sala de conferências, um delegado usuário de saúde sorriu com triunfo: "Isto é democracia, temos o direito de ser tratados como iguais".

\section{Conclusões}

Embora grande parte do foco na literatura sobre instituições participativas no Brasil tem sido nos Conselhos e na agora famosa instituição do orçamento participativo, nossa análise sugere que as contribuições que as conferências fazem para sustentar o modelo do SUS da reforma dos direitos baseados na saúde são uma parte importante da história. Estimulando ondas de engajamento que surtem efeito em todo o País, reunindo centenas de milhares de pessoas para deliberar sobre as políticas de saúde, e criando espaços de mobilização, bem como locais para os movimentos sociais pressionarem suas reivindicações diante do Estado, as conferências são uma instância em que algumas das promessas da democracia radical sobrevivem.

$\mathrm{O}$ que torna as conferências especialmente interessantes a partir de uma perspectiva futura dos sistemas de saúde é o lugar que ocupam dentro de uma arquitetura mais complexa de engajamento público. Essa arquitetura contempla deliberação aberta em um grande número de pessoas (as cerca de 300 mil pessoas, por exemplo, que participaram em conferências municipais e estaduais que antecederam a Conferência Nacional) com mais de 5000 conselhos regularizados, de menor proporção, que reúne mais de $100 \mathrm{mil}$ cidadãos ao lado de funcionários governamentais, a cada mês, para manter o Estado prestando contas sobre os seus compromissos e monitorar os gastos com a saúde. Ela procura ativamente expandir os efeitos democratizantes de engajamento do cidadão para novos atores sociais, por meio de rotação de membros dos conselhos e a eleição de delegados para as conferências em cada 
nível. E, envolvendo representantes ao invés de indivíduos, ela tem o potencial de estimular a criação de novos atores coletivos, mobilizando-os para buscar a realização de compromissos, garantindo um grau de prestação de contas e constitucionalidade. A arquitetura de participação brasileira oferece uma abordagem muito diferente, por exemplo, da abordagem do Reino Unido para o envolvimento do público, em que os cidadãos são consultados como os consumidores individuais dos serviços de saúde: a abordagem baseada em direitos, no Brasil, produz o engajamento de cidadãos, não de "agentes de escolha", como aqueles que devem participar ativamente na definição das políticas, forçando o Estado a prestar contas sobre o que lhes é ofertado. Ela os trata não como "cidadãos ativos" ou "pacientes especialistas" atomizados, que são incentivados a participar na oferta dos serviços dos quais usufruem, mas como "criadores e formadores" (Cornwall \& Gaventa, 2001), que têm um papel vital a desempenhar na gestão dos serviços de saúde. É aqui, talvez, que as lições mais importantes de todas para o desenvolvimento dos sistemas de saúde futuros serão encontradas.

Em um país marcado por profundas desigualdades sociais e de saúde, e uma história de modelos de prestação de serviços de exclusão, as reformas baseadas nos direitos que criou o SUS têm permitido enormes progressos no sentido de tornar uma realidade a atenção primária pública e universal. É importante, no entanto, não exagerar no sucesso: existem, e permanecem, significativas dificuldades em efetivar a perspectiva dos sanitaristas sobre o engajamento dos cidadãos na governança da atenção à saúde. A politização aberta de espaços de deliberação, a "incivilidade" e falta de autonomia da "sociedade civil", arrogância burocrática residual e receios sobre ceder muito controle para o cidadão; esses e outros problemas continuam a afetar o processo de realização dessa ambiciosa experiência em governança democrática. No entanto tem havido ganhos significativos, não menos importantes para os resultados de saúde. Dada a dimensão das mudanças na cultura política e profissional que são necessárias para realmente democratizar a gestão da saúde nesse cenário, esses ganhos são significativos. Em última análise, é a legitimidade política assegurada na institucionalização do controle social da gestão financeira que representa o recurso mais importante no qual o sistema pode se apoiar enquanto amadurece e amplia seu alcance regulamentar.

Inevitavelmente, porém, como o SUS amadurece e chega mais perto de cumprir seu encargo de direitos de saúde para todos, o momento político que lhe permitiu resistir à onda adversa de reformas neoliberais (acima de tudo, para garantir que os gastos com saúde pública recebam sempre uma crescente porcentagem do PIB) 
começa a retroceder. ${ }^{6}$ Como a necessidade de mobilização para sustentar a implantação de serviços básicos recua e a tarefa de priorização entre múltiplas demandas sobre os recursos escassos torna-se mais urgente, a arquitetura de participação do SUS precisa de mudança para sustentar a legitimidade de uma "parceria reguladora" entre Estado e cidadãos que realmente cumpra suas funções. Essa arquitetura tem demonstrado limitaçôes, sobretudo na inclusão e arbitrariedade entre diversas fontes de conhecimento, mas sua própria existência fornece um valioso ponto de partida: o fato de que ela surgiu, evoluiu e se tornou incorporada ao tecido institucional do SUS dá ao Brasil uma enorme vantagem, uma vez que enfrenta o desafio de negociar os pactos sociais que irão definir e manter a forma futura de seu sistema de saúde.

Bloom e Standing (2008) argumentam, em seu artigo de revisão, a favor de uma "abordagem contextual" para sistemas de saúde. A emergência do SUS se deve, indubitavelmente, à convergência de uma série de fatores contextuais e historicamente específicos. Estes incluem o aumento notável de movimentos sociais reivindicando direitos que marcou a década de 1980, o consenso político pós-ditatorial sobre a necessidade de abordar as desigualdades no acesso aos serviços públicos e a combinação de ideologia e pragmatismo que identificou controle social como um mecanismo para preservar a legitimidade do desenvolvimento social estabelecido, usando supervisão do cidadão para dirigir o seu curso e domar seus excessos. Embora essa conjunção de circunstâncias é improvável que volte a ocorrer no Brasil ou em qualquer outro lugar, há muitos contextos nos quais uma explosão de "energia social" (Bebbington \& McCourt, 2007) em torno de lidar com as desigualdades de saúde poderia ser canalizada para a construção de novos pactos capazes de sustentar sistemas de saúde mais equitativos futuramente.

A maior lição do Brasil se encontra no poder de reforma da saúde baseada em direitos para mobilizar cidadãos ao engajamento. Se institucionalizada com sucesso, tal reforma pode gerar a legitimidade política necessária para sustentar o lançamento inicial de serviços e, ao mesmo tempo, incorporar práticas que permitirão o futuro sistema de saúde se adaptar para enfrentar o desafio de perseguir os direitos à saúde para todos em um mundo não igual e cada vez mais em rápida mutação. Considerações contextuais são claramente importantes aqui. Mas há ingredientes de desenho institucional usado para moldar as instituições participativas no Brasil que não têm algo mais geral para oferecer do que o projeto dos sistemas de saúde futuros. Estes incluem

\footnotetext{
6 Na verdade, isso já pode estar acontecendo; participantes de um workshop organizado pelo Conselho Nacional de Saúde, para preparar o caminho para a $13^{a}$ Conferência Nacional de Saúde (realizada em 2007) reportou queda dos níveis de participação nas conferências em vários Estados (Ministério da Saúde, 2006, p. 3) e, no final de 2007, o governo não conseguiu garantir a aprovação do Senado para a renovação da CPMF, imposto sobre transaçóes financeiras, uma importante fonte de financiamento do sistema de saúde.
} 
um quadro jurídico que cria obrigações legais para envolver os cidadãos na deliberação sobre a política de saúde e mantém o Estado pressionado a prestar contas; a criação de uma rede de instituições, desde o nível local até o nacional, dando funcionalidade ao processo através de recursos comprometidos pelo Estado; a combinação de conferências deliberativas em que orientações políticas são determinadas e Conselhos para acompanhar a sua execução; e em ir além do indivíduo atomizado, envolvendo representantes de movimentos sociais, associações de bairros, renovando a filiação regularmente para estender o alcance dos efeitos democratizantes do engajamento.

\section{Agradecimentos}

Precisamos agradecer a muitos colegas brasileiros pelo o seu apoio ao nosso trabalho. Agradecimentos especiais são para a Sílvia Cordeiro e outros colegas no Centro das Mulheres do Cabo, os membros do Conselho Municipal de Saúde do Cabo de Santo Agostinho e Marina Machado, Andrea Giberti e Nilda Rodrigues da Associação Saúde Sem Limites. Somos extremamente gratos aos organizadores da $12^{a}$ Conferência Nacional de Saúde, da $6^{a}$ Conferência Municipal de Saúde de Cabo e da $4^{\text {a }}$ Conferência Nacional de Saúde Indígena (em particular, Artur Custódio Moreira de Sousa, Luciana Benevides e Ademir Gudrin) por terem facilitado o acesso aos processos de Conferência. A pesquisa na qual este artigo se baseia foi financiada pelo Centro de Pesquisa de Desenvolvimento em Cidadania, Participação e Accountability (Cornwall) e o Conselho de Economia e Pesquisa Social do Reino Unido (Shankland).

\section{Referências}

Arretche, M. (2003). Financiamento federal e gestão local de políticas sociais: o difícil equilíbrio entre regulação, responsabilidade e autonomia. Ciência e Saúde Coletiva, 8 (2), 331-345.

Athias, R. \& Machado, M. (2001). A saúde indígena no processo de implantação dos distritos sanitários: temas críticos e propostas para um diálogo interdisciplinar. Cadernos de Saúde Pública, 17 (2), 425-431.

Bebbington, A. \& McCourt, W. (2007). Explaining (and obtaining) development success. In A. Bebbington \& W. McCourt (Eds.). Development 
success: statecraft in the South. (pp. 211-245). London: Palgrave.

Bloom, G. \& Standing, H. (2008). Future health systems: why future? Why now? Social Science \& Medicine, 66 (10), 2067-2075.

Carvalho, G. \& Santos, L. (1995). Sistema Único de Saúde: comentários à Lei Orgânica de Saúde. In Coelho, V. S. (2004). Brazil's health councils: the challenge of building participatory political institutions. IDS Bulletin, 35 (2), 33-39.

Coelho, V. S. (2004). Brazil's health councils: the challenge of building participatory political institutions. IDS Bulletin, 35 (2), 33-39.

Coelho, V. S. (2006). Brazilian health councils: including the excluded? In A. Cornwall \& V. S. Coelho (Eds.). Spaces for change? The politics of participation in new democratic arenas. (pp. 33-54). London: Zed Books.

Cohen, J. \& Sabel, C. (1997). Directly-deliberative polyarchy. European Law Journal, 3 (4), 313-342.

Cornwall, A. \& Gaventa, J. (2001). From users and choosers to makers and shapers: repositioning participation in social policy. IDS Bulletin, 31 (4), 5062.

Cornwall, A. (2006). Democratizing the governance of health services: experiences from Brazil. In A. Cornwall \& V. S. Coelho (Eds.). Spaces for change? The politics of citizen participation in new democratic arenas. (pp. 155179). London: Zed Books.

Costa, M. (2007). A luta pela reforma sanitária: direitos em saúde. In J. Romano, R. Athias \& M. Antunes (Eds.). Olhar critico sobre participação e cidadania: trajetórias de organização e luta pela redemocratização da governança no Brasil. (pp. 133-159). São Paulo: Expressão Popular.

Costa, R. C. R. (2002). Descentralização, financiamento e regulação: a reforma do sistema público de saúde no Brasil durante a década de 1990. Revista de Sociologia e Politica, (18), 49-71.

Dal Poz, M. R. \& Pinheiro, R. (1998). A participação dos usuários nos conselhos municipais de saúde e seus determinantes. Ciência e Saúde Coletiva, 3 (1), 28-30.

Dias, S. (2006, 5 de setembro). Saúde: índio quer controle social. Com 
Ciência, (9). Disponível em: http://comciencia.br/comciencia/?section=9\&r eportagem $=165$.

Fung, A. \& Wright, E. (2003). Deepening democracy: institutional innovations in empowered participatory governance. London: Verso.

Haas, P. M. (1992). Epistemic communities and international policy coordination e introduction. International Organization, 46 (1), 1-35.

Hirschmann, A. (1970). Exit, voice and loyalty. Cambridge: Harvard University Press.

Instituto Brasileiro de Geografia e Estatística. (2005). Pesquisa nacional por amostra de domicílios: acesso e utilização dos serviços de saúde. Rio de Janeiro: IBGE.

Instituto Socioambiental. (2006, 23 de junho). Cronologia do caos. Notícias Socioambientais, 23.

Melo, M. \& Rezende, F. (2004). Decentralization and governance in Brazil. In J. Tulchin \& A. Selee (Eds.). Decentralization and democratic governance in Latin America. (pp. 37-66). Washington: Woodrow Wilson Center.

Melo, M. (1993). Anatomia do fracasso: intermediação de interesses e a reforma das políticas sociais na Nova República. Dados: Revista de Ciências Sociais, 36 (1), 119-164.

Ministério da Saúde. (2007). Indicadores e dados básicos (IDB): Brasil 2006. Brasília: Ministério da Saúde. Disponível em: http://tabnet.datasus. gov.br/cgi/ idb2006/matriz.htm.

Ministério da Saúde. Conselho Nacional de Saúde. (2004). Propostas relacionadas aos povos indígenas aprovadas na $12^{a}$ Conferência Nacional de Saúde. Brasília: CNS. Disponível em: http://conselho.saude.gov.br/comissao/ docs/texto saudeindio.doc.

Ministério da Saúde. Conselho Nacional de Saúde. (2006). Relatório da Oficina Permanente Rumo à $13^{a}$ Conferência Nacional de Saúde. Brasília: CNS. Disponível em: http://conselho.saude.gov.br/ultimas_noticias/2006/ relatoriooficina.doc.

Oliveira, F. (2002). Saúde da população negra: Brasil: ano 2001. Brasília: PAHO.

Santos, N. Rodrigues dos (2000). Implantação e funcionamento dos Conselhos de Saúde no Brasil. In M. do C. A. Carvalho \& A. C. C. Teixeira 
(Eds.). Conselhos gestores de políticas públicas. (pp. 15-21). São Paulo: Polis.

Shankland, A. \& Athias, R. (2007). Decentralisation and difference: indigenous peoples and health system reform in the Brazilian Amazon. IDS Bulletin, 38 (1), 77-88.

Shankland, A. \& Cornwall, A. (2007). Realising health rights in Brazil: the micropolitics of sustaining health system reform. In A. Bebbington \& W. McCourt (Eds.). Development success: statecraft in the South. (pp. 163-188). London: Palgrave.

Silva, P. L. B. (2003). Serviços de saúde: o dilema do SUS na nova década. São Paulo em Perspectiva, 17 (1), 69-85.

Tatagiba, L. (2002). Os conselhos gestores e a democratização das políticas públicas no Brasil. In E. Dagnino (Ed.). Sociedade civil e espaços públicos no Brasil. (pp. 47-103). São Paulo: Paz e Terra.

Viana, A. L. Ávila (1998). Desenho, modo de operação e representação de interesses do sistema municipal de saúde e o papel dos conselhos de saúde. Ciência e Saúde Coletiva, 3 (1), 20-23.

Weyland, K. (1995). Social movements and the state: the politics of health reform in Brazil. World Development, 23 (10), 1699-1712. 